\title{
PROJETO JOVENS GUARDAS NA RESERVA ECOLÓGICA DE GUAPIAÇU (REGUA): PAPEL SOCIOAMBIENTAL DAS ATIVIDADES EXERCIDAS À LUZ DA EDUCAÇÃO AMBIENTAL CRÍTICA
}

\author{
Maiara Pereira Barreto ${ }^{1}$ \\ Rosane Moreira Silva de Meirelles ${ }^{2}$
}

Resumo: A Educação Ambiental (EA), em espaços não-formais de ensino, à medida que ultrapassam os muros da escola e integrados aos espaços formais de ensino buscam atender melhor as demandas socioambientais locais. Analisamos as atividades e percepções dos participantes do "Projeto Jovens Guardas", na Reserva Ecológica de Guapiaçu (REGUA), que proporciona aos participantes experiências ligadas à conservação do seu território. Os resultados sugerem influências positivas do projeto nos alunos. Porém, a partir de uma leitura crítica da EA, as atividades do projeto se distanciam de um discurso sobre conflitos sociais, históricos e políticos do território destes alunos. Os resultados contribuem para a reflexão sobre o protagonismo juvenil e suas relações com o seu ambiente.

Palavras-chave: Educação Ambiental Crítica; Espaços Não-formais de Ensino; Protagonismo Juvenil.

Abstract: Environmental education, in non-formal teaching spaces, as they go beyond school walls and integrated with formal teaching spaces, seek to improve the local socio-environmental demands. We analyzed the activities and perceptions of the participants of the "Projeto Jovens Guardas", at Reserva Ecológica de Guapiaçu (REGUA), which provides participants with experiences related to the conservation of their territory. The results suggest positive influences of the project on the students. However, from a critical reading of the EA, the activities of the project distance themselves from a discourse on social, historical and political conflicts in the territory of these students. The results contribute to the reflection on the youth protagonism and its relations with their environment.

Keywords: Critical Environmental Education, Non-formal Teaching Spaces, Youth Protagonism.

\footnotetext{
${ }^{1}$ Programa stricto sensu em Ensino em Biociências e Saúde - PG-EBS - LITEB - IOC/FIOCRUZ. E-mail: mai.silvah@hotmail.com.

2 Programa stricto sensu em Ensino em Biociências e Saúde - PG-EBS - LITEB - IOC/FIOCRUZ; Departamento de Ensino de Ciências e Biologia - DECB/UERJ. E-mail: rosanemeirelles@gmail.com
} 


\section{Introdução}

A Educação Ambiental (EA) é considerada uma ferramenta importante e necessária desde o início dos debates ambientais no mundo moderno - por volta do início dos anos 70 - ainda que sua institucionalização tenha ocorrido mais tardiamente nas conferências mundiais sobre o ambiente (TANNOUS; GARCIA, 2008). Os autores citam, ainda, que a EA é um forte exemplo onde se torna possível a elaboração de práticas com potencial de organização dos sujeitos para enfrentamento da crise socioambiental. Sua premissa de criação concentra-se na ideia de que o debate sobre a crise socioambiental mundial chegasse até as populações, permitindo a compreensão e participação de todos os atores sociais nos planos estratégicos de enfrentamento dessa crise (TANNOUS; GARCIA, 2008; MENDONÇA; CÂMARA, 2012).

Ainda que, mais comumente, encontremos a EA atrelada ao ambiente escolar, também é possível encontrar ações de EA em espaços não-formais de ensino, especialmente em ambientes com uma notável preservação da natureza (QUEIROZ; GUIMARÃES, 2016). Nesses espaços, se busca ampliar o debate socioambiental que a escola, sozinha, não dá conta de discutir. Sendo assim, os dois espaços - a escola e os espaços externos a ela - podem se integrar e interagir entre si (GUIMARÃES, 2007).

Um exemplo disso é o Projeto Jovens Guardas (PJG), uma realização da Reserva Ecológica de Guapiaçu (REGUA), localizada no município de Cachoeiras de Macacu, no Rio de Janeiro. O projeto foi criado em 2004 e acontece na REGUA todas as sextas-feiras, das $14 \mathrm{~h}$ às $16 \mathrm{~h}$, durante 0 ano letivo. Os alunos participantes do projeto são convidados a partir da sua matrícula em escola regulares municipais da região. O objetivo do projeto é "sensibilizar e modificar as percepções dos jovens estudantes e moradores do entorno (bairros Matumbo e Guapiaçu) da REGUA sobre as questões ligadas à conservação da Mata Attântica na alta bacia do Rio Guapiaçu", a partir da necessidade de "oferecer uma oportunidade de maior contato dos jovens da alta bacia com os trabalhos de conservação desenvolvidos na Reserva" (REGUA, 2019).

Neste contexto, esta pesquisa se dedicou a investigar as percepções dos alunos do PJG acerca das atividades que participam na reserva, assim como o papel socioambiental que o projeto desempenha em suas formações.

\section{Metodologia}

Esta pesquisa foi aprovada pelo Comitê de Ética em Pesquisa (CEP), sob o parecer no 3.152.221. Nela, analisou-se a relação entre a REGUA e sua comunidade do entorno, através das atividades de Educação Ambiental (EA). Foi utilizada a abordagem metodológica qualitativa, no intuito de compreender a relação entre variáveis de uma realidade e compreender fenômenos através da coleta de dados narrativos individuais (GÜNTHER, 2006). 
A coleta de dados foi realizada através da observação participante das atividades e entrevista semiestruturada com os jovens integrantes do projeto. Dentro do período ativo do projeto, foram realizadas um total de oito visitas, uma por mês, totalizando 8 meses. As atividades que os alunos participam são desenvolvidas ao longo do ano letivo variando a temática a cada mês (BARRETO; MEIRELLES, 2019; BARRETO, 2019).

O acompanhamento e as observações foram realizados a fim de se obterem registros acerca da rotina dos jovens no projeto, tipos de atividades realizadas, espaços e materiais utilizados e meios de participação dos jovens. Esta etapa da pesquisa foi realizada dentro do período de 2 horas, correspondente ao tempo de ocorrência do encontro semanal. Com os registros realizados, a partir das observações, foi possível uma comparação com os dados obtidos no período de entrevista com os alunos, ampliando as informações sobre como funciona o projeto, como ocorre a participação dos alunos e o interesse dos mesmos pelas atividades, inferindo na relação que os mesmos possuem com a reserva e no alcance dos objetivos do projeto.

Já a etapa da entrevista consistiu em uma gravação em áudio, com duração média de 15 minutos por entrevistado(a), elaborada de maneira semiestruturada. Todos os alunos participantes do projeto foram convidados à coleta de dados na etapa de entrevista, mediante autorização de seus responsáveis. Seis - de um total de 13 alunos - demonstraram interesse em participar desta etapa. O grupo entrevistado foi formado por cinco alunos ativos no projeto e um ex-aluno - mas que ainda atua em alguns momentos como auxiliar do educador ambiental responsável pelo projeto. A partir dos dados gerados, foi analisado de que forma o projeto tem contribuído para a relação dos jovens com a reserva (enquanto moradores do entorno) e com a comunidade em que residem.

Durante a organização dos dados, foi traçado o perfil dos jovens, levando em consideração gênero, idade e tempo de participação no projeto. A análise de dados foi realizada utilizando a tematização, proposta por Fontoura (2011), que consiste em uma sistematização dos dados qualitativos obtidos na pesquisa, em alguns passos. Sendo assim, com base em Fontoura (2011), a análise dos dados deste trabalho incluem: transcrição do material, leitura do material, recorte de passagens significativas do texto (unidades de registro), levantamento dos temas, definição de unidades de contexto (trechos das unidades de registro relevantes para o objeto da pesquisa) e, por fim, interpretação à luz dos referenciais teóricos.

O primeiro passo foi composto pela transcrição de todos os áudios gravados nas entrevistas, seguido de duas leituras atentas do material, sendo a segunda leitura onde ocorreu o recorte de passagens significativas do texto (unidades de registro), com a finalidade de levantamento dos temas. A escolha dos temas teve como critério a pertinência com o objetivo do estudo, logo, eles foram identificados de acordo com as falas dos alunos, que evidenciavam suas percepções acerca das atividades realizadas no PJG. 
Após o levantamento dos temas, foram definidas as "unidades de contexto". As unidades de contexto referem-se à seleção de trechos longos e relevantes da fala dos alunos. Por fim, os resultados obtidos foram interpretados à luz de autores da EA crítica, uma vertente da EA que considera os problemas ambientais integrados aos processos sociais $e$ suas desigualdades. A EA crítica considera, também, os problemas socioambientais como frutos de um sistema capitalista que explora em excesso os recursos naturais e os distribui desigualmente, ao mesmo tempo em que atribui a maior parcela da culpa aos mais pobres e marginalizados e os exclui da tomada de decisões (LOUREIRO, 2003; LOUREIRO, 2019). Sendo assim, se espera que as práticas pedagógicas oriundas desta corrente sejam trabalhadas a partir de uma discussão mais ampla dos problemas ambientais, levando em consideração também as suas dinâmicas sociais (SAUVÉ, 2006).

\section{Resultados e Discussão}

Quanto ao gênero dos alunos participantes da pesquisa, a maioria enquadra-se no gênero masculino. A idade dos participantes variou entre $9 \mathrm{e}$ 17 anos (atuantes no projeto), além do ex-aluno que possui 24 anos. Por fim, o tempo de participação no projeto mostrou uma variação entre menos de 1 ano à 2 anos (para os atuantes) e 6 anos (para o ex-aluno). $O$ quadro abaixo (Quadro 1) apresenta o conjunto de informações acerca do perfil dos participantes, organizado por faixa etária (do mais novo para o mais velho) e não corresponde a ordem de entrevista:

Quadro 1: Perfil dos jovens guardas entrevistados.

\begin{tabular}{|c|c|c|c|c|c|c|}
\hline Idade & 9 anos & 9 anos & 13 anos & 14 anos & 17 anos & 24 anos \\
\hline Gênero & Feminino & Feminino & Masculino & Masculino & Masculino & Masculino \\
\hline $\begin{array}{c}\text { Tempo } \\
\text { de } \\
\text { projeto }\end{array}$ & $\begin{array}{c}\text { Menos de } \\
1 \text { ano }\end{array}$ & $\begin{array}{c}\text { Menos de } \\
1 \text { ano }\end{array}$ & 2 anos & 2 anos & 2 anos & 6 anos \\
\hline Situação & $\begin{array}{c}\text { Aluna } \\
\text { ativa }\end{array}$ & $\begin{array}{c}\text { Aluna } \\
\text { ativa }\end{array}$ & Aluno ativo & Aluno ativo & Aluno ativo & Ex-aluno \\
\hline
\end{tabular}

De acordo com a análise de tematização proposta por Fontoura (2011), foram realizados recortes das entrevistas realizadas com os alunos do Projeto Jovens Guardas (PJG), destacando as unidades de contexto, relacionadas aos temas levantados para esta pesquisa. Os alunos entrevistados foram identificados em suas falas com a sigla JG, seguido de um número - entre 1 e 6 - para representá-los.

A participação no PJG é marcada por uma rotina semanal, abordando temáticas previamente elaboradas pelo coordenador do grupo em um roteiro. 
De acordo com os trechos abaixo, identificamos a predominância de temáticas ligadas à ecologia e aspectos naturalistas da região:

JG1: "A gente estudava liquens, biodiversidade, biologia também era muito interessante, plantar árvore também e ver os animais que tem aqui na nossa região que a gente tem que cuidar também [...] A gente ia nas comunidades fazer a limpeza dos rios [...]"

JG4: "A gente anda pela trilha, vamos ver os animais, como é que funciona. Nós começa a fazer um negócio lá na sementeca, ver sementes, pra depois trazer pra plantar."

Essa predominância do discurso mais inclinado a uma corrente conservacionista releva uma simplificação da problemática ambiental, desvinculando-a de processos sociais, políticos e históricos (BRESOLIN; ZAKRZEVSKI; MARINHO, 2010; LAYRARGUES; LIMA, 2014) do território onde os jovens residem e sua relação com a reserva. Tais dados não significam que o estudo de assuntos ecológicos não tenha sua importância e seu valor nos projetos de Educação Ambiental. No entanto, desvinculá-lo da realidade social em que vivem os participantes do projeto, dificulta a compreensão, por parte dos alunos, da sua realidade, da mesma forma em que pode dificultar a sua transformação (BRESOLIN; ZAKRZEVSKI; MARINHO, 2010).

No entanto, apesar da predominância do discurso mais conservacionista, também foi possível encontrar a presença de alguns valores, na intenção de auxiliar os alunos em sua formação cidadã. Um exemplo é explicitado pelo primeiro trecho, na fala do JG1, o qual cita a ida à comunidade para realizar limpeza dos rios. Ao longo da observação participante, em alguns momentos, também foi possível identificar o desenvolvimento de alguns valores, marcados por falas do condutor das atividades sobre a importância do respeito pela comunidade e saberes do campo.

Diante de uma rotina pré-estabelecida, concordamos com Sauvé (2006) quando aponta para a importância de um maior envolvimento de todos os atores sociais, também, na tomada de decisões. Isso se intensifica ainda mais quando se trata de atores sociais na fase juvenil, que corresponde a uma fase social de transição, na qual possuem vigor para os processos de transformação social ao mesmo tempo em que "refletem estruturas e processos sociais" (SILVA; HIGUCHI; FARIAS, 2015).

Nesse sentido, dar voz e espaço aos jovens e permitir um maior protagonismo juvenil - no que diz respeito à participação na construção do seu contexto de aprendizagem e atuação - contribui para o fortalecimento do sentimento de pertencimento em relação ao seu ambiente (QUEIROZ; GUIMARÃES, 2016; GRAÚDO; GUIMARÃES, 2017), para a sua formação 
cidadã e seu desenvolvimento como sujeitos ecológicos, mas também sociais, históricos e políticos (SILVA; HIGUCHI; FARIAS, 2015; SANTANA; SANTOS, 2016).

Baseado no exposto acima, identificamos nos alunos do PJG potencial de colaboração na construção do projeto, diante de falas que expõem desejos e sugestões para melhoria das atividades. Este fato pode ser percebido ao serem questionados sobre o que acham da rotina estabelecida, fazendo conexões com atividades que gostariam de realizar no projeto, explicitados pelos trechos a seguir:

JG1: “[...] Eu queria pedir é pra gente buscar aprender mais coisas fora da comunidade, na cidade, pra gente levar pra lá as coisas de onde a gente mora [...] e aprender mais coisas pra contribuir com a comunidade."

JG3: "Eu acho que a gente podia visitar mais lugares como a REGUA."

JG4: "Ir pra lugares como o Três Picos. Pra gente não ficar só aqui também, não dá muito certo."

A fala do JG1, em especial, nos revela um dado muito interessante, pois o aluno destaca um interesse em aprender fora da comunidade para contribuir com a própria comunidade, o que pode significar a esperança dos alunos em ter o PJG como potencial de transformação do seu próprio território.

Quanto aos demais jovens participantes da pesquisa, suas falas parecem exprimir um desejo de realizar atividades que corroborem com o que já é realizado por eles, ao mesmo tempo em que lhes ofereça oportunidades de lazer e quebra da rotina. No senso comum, atividades de lazer não parecem possuir potencial de problematização e transformação social. No entanto, elas carregam consigo conteúdos e conhecimentos da prática social que podem fortalecer o enfrentamento dos problemas socioambientais detectados na região (LOUREIRO; TOZONI-REIS, 2016).

Quanto à influência do projeto sobre o cotidiano dos jovens, como era esperado, diante das investigações anteriores, os dados sugerem impacto nas percepções ecológicas dos jovens sobre o ambiente. Assim, ao serem perguntados sobre o que eles acham que mudaram neles, desde a entrada e participação no projeto, os alunos fizeram as seguintes colocações:

JG1: “[...] Antes eu não tinha essa visão assim 'Ah, o lixo serve pra isso' [...] hoje em dia a gente usa papelão pra fazer reciclável, pra fazer até uma caneta reciclável. Essa consciência ambiental. [...] (Hoje) eu sou bem participativo em casa também. Acho que isso melhorou, eu era muito tímido e hoje sou mais comunicativo. O professor me colocou 
como auxiliar dele pra melhorar isso, eu era muito quieto, hoje sou mais falante [...]."

JG2: "Me ajuda a pensar mais sobre a natureza. Antigamente não tinha esse negócio de se tivesse cortando uma árvore, nem ligava, mas agora eu penso duas vezes antes de cortar."

JG3: "Na minha opinião, cara, eu acho que maturidade, cresci mais [...] Quando eu era um pouco mais novo, eu pegava um pé de árvore, aí cortava [...] Eu não faço isso mais não, nem consigo. Com esse projeto agora, mudou o pensamento."

JG4: "Maturidade [...] Também cortava bastante árvore, agora não faço mais."

JG5: "Eu jogava plástico na rua, agora se tiver uma sacola, eu boto no bolso."

JG6: "Antigamente eu tinha medo dos animais: cobra, onça... agora eu vejo que eles são animais que só querem o cantinho deles."

A partir das falas dos estudantes, percebe-se que estes tem voltado suas preocupações, predominantemente, para a conservação/preservação do ambiente. Isso se dá, possivelmente, pelo próprio foco do projeto, que também se encontra, predominantemente, em uma esfera conservacionista. Assim, é esperado que as escolhas pedagógicas feitas para o projeto influenciam na aprendizagem dos alunos e na forma de compreender o ambiente a sua volta (CARVALHO, 2001), nesse caso, pautado principalmente em difusão de aspectos ecológicos do ambiente.

No entanto, alguns jovens também mencionaram aspectos pessoais do seu desenvolvimento (amadurecimento e melhora na comunicação, aprimorados, segundo eles, através da ajuda do projeto). Este resultado revela que, mesmo pautado em questões mais conservacionistas, o PJG possibilitou aos estudantes a vivência e a experimentação de sentidos, através dos trabalhos de campo. Dessa forma, o projeto pôde contribuir também para o desenvolvimento pessoal dos participantes (QUEIROZ; GUIMARÃES, 2016).

\section{Conclusões}

A ideia de uma EA como um espaço de debate sobre as questões socioambientais tem ganhado cada vez mais dimensão em nossa sociedade e possibilitado o aumento de atividades voltadas para essa temática. Assim, o Projeto Jovens Guardas (PJG), da Reserva Ecológica de Guapiaçu (REGUA), dentro do seu objetivo de discutir questões ligadas à conservação da Mata Atlântica para os jovens da região, tem se mostrado como um relevante 
ambiente de ensino-aprendizagem para a conservação da região, que possui uma notável paisagem de Mata Atlântica preservada.

É possível perceber, através dos dados apresentados, que os jovens demonstram interesse pelo projeto e que este tem contribuído para a formação desses jovens, seja em alguns aspectos sociais, mas, principalmente, nos aspectos ecológicos. Este fato se deve à predominância do caráter informativo e conservacionista observado nas atividades, o que também foi relatado nas entrevistas.

As atividades de EA voltadas para o público juvenil podem propiciar a "multiplicação de mudanças em diferentes cenários, seja social e/ou ambiental", com potencial para levar os jovens a atuarem ativamente na transformação da sua realidade socioambiental (SILVA; HIGUCHI; FARIAS, 2015, p 4).

A partir de uma perspectiva crítica da EA, é pertinente que haja uma ampliação do diálogo com esses jovens, inserindo conflitos e problemáticas sociais próprias do seu território, que contribuem para o fortalecimento da crise ambiental. Dessa forma, entende-se que através da ampliação do debate e do oferecimento de maior protagonismo dos jovens, é possível construir elementos que favoreçam maior possibilidade de transformação do seu ambiente.

Diante do exposto, percebemos a importância de projetos com atividades de ensino em ambiente não-formal, contribuindo para o desenvolvimento e formação de estudantes da região, como aliado extensionista da escola. Assim, projetos como o Projeto Jovens Guardas possuem um grande potencial de se tornarem instrumentos de transformação social em seu território, sendo os elementos da Educação Ambiental crítica excelentes caminhos de reflexão e construção dessas mudanças, por permitirem um entendimento e enfrentamento dos problemas ambientais em esferas mais amplas (LAYRARGUES; LIMA, 2014).

Dessa forma, como perspectivas futuras, os dados expostos neste artigo servirão como base para a criação de uma proposta compartilhada de ensino, fundamentada pela Educação Ambiental crítica no local de atividades pesquisado, a fim de por em prática e analisar os potenciais expostos acima.

\section{Referências}

BARRETO, M. P. Percepções e práticas de ensino em uma reserva ambiental e sua comunidade do entorno: análise da relação reserva-comunidade a partir da Educação Ambiental crítica Dissertação (mestrado em Ensino em Biociências e Saúde) - Instituto Oswaldo Cruz, Fundação Oswaldo Cruz (FIOCRUZ), Rio de Janeiro, 2019. Disponível em https://www.arca.fiocruz.br/handle/icict/43827. Acesso em março de 2021 
BARRETO, M. P.; MEIRELLES, R. M. S. Trilhando caminhos para o educador ambiental: reflexões sobre a práxis a partir da experiência da Reserva Ecológica de Guapiaçu (REGUA). In: VI CONEDU - Congresso Nacional de Educação. Fortaleza - Ceará. Anais. Ceará: Centro de Eventos do Ceará, 2019. Disponível em http://www.editorarealize.com.br/artigo/visualizar/62767. Acesso em março de 2021.

BRESOLIN, A. J; ZAKRZEVSKI, S. B. B; MARINHO, J. R. Percepção, comunicação e Educação Ambiental em Unidades de Conservação: um estudo no Parque Estadual de Espigão Alto - Barracão/RS - Brasil. Perspectiva, Erechim, v 34, p 103-114, 2010.

CARVALHO, I. C. de M. Qual Educação Ambiental? Elementos para um debate sobre educação. Agroecologia e Desenvolvimento Rural Sustentável. Porto Alegre, v 2, n 2, 2001.

FONTOURA, H. A. Tematização como proposta de análise de dados na pesquisa qualitativa. Formação de professores e diversidades culturais: múltiplos olhares em pesquisa. Niterói: Intertexto, p 61-82, 2011.

GRAÚDO, D; GUIMARÃES, M. Pertencimento e Educação Ambiental: reflexões iniciais. Anais do IX EPEA - Encontro de Pesquisa em Educação Ambiental. Juiz de Fora - MG. Universidade Federal de Juiz de Fora, 2017.

GUIMARÃES, M. Educação Ambiental: participação para além dos muros da escola. In: MELLO, S.S; TRAJBER, R. (Coord.). Vamos cuidar do Brasil: conceitos e práticas em Educação Ambiental na escola. Brasília: Ministério da Educação: Ministério do Ambiente: UNESCO, p 85-93, 2007.

GÜNTHER, H. Pesquisa qualitativa versus pesquisa quantitativa: está é a questão. Psicologia: teoria e pesquisa, vol 22, n 2, p 201-210, 2006.

LAYRARGUES, P. P; LIMA, G. F. da C. The Brazilian environmental education macro-political-pedagogical trends. Ambiente \& Sociedade, v 17, n 1, p 23-40, 2014.

LOUREIRO, C. F. B. Premissas teóricas para uma Educação Ambiental transformadora. Ambiente e Educação, Rio Grande, v 8, p 37-54, 2003.

LOUREIRO, C. F. B; TOZONI-REIS, M. F. de C. Teoria social crítica e pedagogia histórico-crítica: contribuições à Educação Ambiental. Rev. Eletrônica Mestr. Educ. Ambiental. Ed. Especial, 2016.

LOUREIRO, C. F. B. Questões ontológicas e metodológicas da Educação Ambiental crítica no capitalismo contemporâneo. Rev. Eletrônica Mestr. Educ. Ambiental. Rio Grande, v 36, n 1, p 79-95, 2019.

MENDONÇA, D.J.F.; CÂMARA, R.J.B. Educação Ambiental em Unidades de Conservação: um Estudo sobre Projetos Desenvolvidos na APA do Maracanã. In: Simpósio de Excelência em Gestão e Tecnologia - SEGET, 2012, Resende - Rio de janeiro. Anais. Rio de Janeiro: AEDB, 2012. 
QUEIROZ, E. D. de; GUIMARÃES, M. O trabalho de campo em Unidades de Conservação como ambiente educativo e estratégia pedagógica fundamental para uma formação diferenciada em Educação Ambiental. Revista Pol. Publ, São Luís. Número especial, p 421-425, 2016.

REGUA. Educação Ambiental. Rio de Janeiro, 2019. Disponível em: HTTP://regua.org.br/conservacao/educacao/jovens-guardas. Acesso em março de 2021.

SANTANA, G. R. de A; SANTOS, J. U. dos. O protagonismo juvenil na conservação da Área de Proteção Ambiental Costa dos Corais. Revista Brasileira de Educação Ambiental, São Paulo, v 11, n 1, p 327-334, 2016.

SAUVÉ, L. A. investigación universitaria en educación ambiental: tendencias teóricas e metodolóxicas nas comunidades científicas francófonas. El marco del II Seminario Compostela de investigación en educación ambiental e para la sostenabilidad. Departamento Teoría e Historia de Educación, Universidade de Santiago de Compostela, 2006.

SILVA, W. G. da S; HIGUCHI, M. I. G; FARIAS, M. S. M de. Educação Ambiental na formação psicossocial dos jovens. Ciênc. Educ., Bauru, v 21, n 4, p 1031-1047, 2015.

TANNOUS, S; GARCIA, A. Histórico e evolução da Educação Ambiental, através dos tratados internacionais sobre o ambiente. Nucleus, v 5, n 2, p 114, 2008. 